\title{
Aplicação de uma órtese funcional para mão em indivíduos com lesão do plexo braquial*
}

\author{
Application of a functional hand orthosis in \\ individuals with brachial plexus injuries
}

\author{
Kátia Vanessa Pinto de Meneses ${ }^{1}$, Daniel Neves Rocha², Fábio Lúcio \\ Corrêa Júnior ${ }^{2}$, Tálita Sono ${ }^{2}$, Ana Luiza Oliveira ${ }^{3}$, Marcos Pinotti ${ }^{4}$
}

\begin{abstract}
MENESES, K. V. P.; ROCHA, D. N.; CORRÊA JÚNIOR, F. L.; SONO, T.; OLIVEIRA, A. L.; PINOTTI, M. Aplicação de uma órtese funcional para mão em indivíduos com lesão do plexo braquial. Rev. Ter. Ocup. Univ. São Paulo, v. 23, n. 1, p. 34-43, jan./abr. 2012.
\end{abstract}

\begin{abstract}
RESUMO: Uma das patologias que causam grande incapacidade e que afetam diretamente na participação social do indivíduo é a lesão do plexo braquial. No processo de reabilitação de indivíduos que sofreram lesão do plexo braquial, órteses são comumente utilizadas como recursos terapêuticos. Porém a maioria das órteses utilizadas nas lesões do plexo braquial, são usadas com objetivo de posicionar o membro superior a fim de evitar deformidades e aliviar a dor, sem oferecer funcionalidade ao membro lesado. O objetivo deste trabalho foi descrever os primeiros testes de um protótipo de órtese funcional para mão, definida como Luva Funcional, em indivíduos adultos com paralisia em mão e punho, devido a lesão do plexo braquial. O trabalho consistiu em estudo experimental, onde participaram três pacientes com lesão de plexo braquial. Foram utilizados três instrumentos: Teste de Função Unimanual, Teste de Função Bimanual e Questionário de Satisfação. Os resultados demonstraram que os pacientes conseguiram controlar a abertura e o fechamento da órtese por meio de sinais mioelétricos captados pelos eletrodos de superfíce colocados sobre a musculatura selecionada. Eles conseguiram segurar e soltar objetos utilizando a órtese Luva Funcional e conseguiram realizar atividades que exigem o uso de duas mãos. Todos os pacientes demonstraram alto índice de satisfação com o uso da órtese Luva Funcional.
\end{abstract}

DESCRITORES: Equipamentos de auto-ajuda; Luvas protetoras/utilização; Plexo braquial/lesões, Reabilitação.

\footnotetext{
* Este trabalho é parte da Tese de Doutorado intitulada: “Avaliação funcional de uma órtese para mão com músculos artificiais eletromecânicos em pacientes com lesão de plexo braquial” (MENESES, 2008). Partes deste trabalho foram apresentadas no Technology and Medical Sciences International, ocorrido em setembro de 2008, Diamantina, Brasil e no $15^{\text {th }}$ Congresso of the World Federation of Occupational Therapists e XV Congresso de La Federación Mundial de Terapeutas Ocupacionales, ocorrido em maio de 2010 em Santiago, Chile. 1. Terapeuta Ocupacional, Mestre e Doutora em Bioengenharia pela UFMG, Professor Adjunto do Curso de Terapia Ocupacional da Universidade de Brasília.

2. Engenheiro, Doutor em Engenharia Mecânica pela UFMG.

3. Aluno de graduação em Terapia Ocupacional - UFMG.

4. Engenheiro, Docente do Departamento de Engenharia Mecânica da UFMG; Coordenador do Laboratório de Bioengenharia da UFMG. Endereço para correspondência: Kátia Vanessa Pinto de Meneses. Av. Flamboyant, lote 22, bloco C, apto 1101, Águas Claras, Brasília, DF. CEP-71917000. E-mail: katiavpmeneses@gmail.com
} 


\section{INTRODUÇÃO}

$\mathrm{D}$ e acordo com a Organização Mundial de Saúde (WORLD HEALTH ORGANIZATION, 2002), a saúde pode ser afetada pela incapacidade de desempenhar atividades e participar em situações da vida. Uma das patologias que causam incapacidade e que podem afetar diretamente na participação social do indivíduo é a lesão do plexo braquial. A grande maioria das lesões do plexo braquial na população adulta resulta de acidentes de trânsito, particularmente os acidentes de motocicletas em alta velocidade. Outras causas podem incluir acidentes de bicicleta, atropelamentos, quedas de peso sobre o ombro, lesões com máquinas em indústrias, quedas de altura, ferimentos por armas de fogo e facas (CONCEIÇÃO, 2005; LEFFERT, 1995). Essas lesões podem causar variados graus de paralisias e alterações sensitivas, podendo afetar todo o membro superior (braço, cotovelo, punho, mão e dedos). A perda da função no membro lesado ocorre de forma repentina causando grande dificuldade de adaptação do paciente à sua nova condição física. A população adulta atingida é em sua maioria jovens, do sexo masculino, e que estão iniciando sua carreira profissional (CONCEIÇÃO, 2005).

Segundo Midha (1997), a taxa de incidência estimada nos Estados Unidos está entre 0,6 a 3,9 por 100.000 habitantes ao ano. Em seu estudo, a partir de uma amostra de pacientes politraumatizados, Midha (1997) encontrou uma incidência de 1,2\% deste tipo de lesão. Em um estudo realizado no Distrito Federal, Flores (2006) encontrou uma incidência aproximada de 1,75 casos por 100.000 habitantes ao ano.

Mesmo com os avanços em procedimentos de diagnóstico e técnicas cirúrgicas durante as últimas décadas, o tratamento das lesões do plexo braquial ainda permanece um grande desafio (ÖGCE; ÖZYALÇIN, 2000). A melhora da função após procedimentos cirúrgicos pode levar muito tempo e, em muitos casos, os resultados não são satisfatórios (HOFFER et al., 1981; SALTER, 2001; SLACK; BERBRAYER, 1992; ÖGCE; ÖZYALÇIN, 2000). O prognóstico para a recuperação da função é ruim, particularmente abaixo do cotovelo (SALTER, 2001), como no punho, na mão e nos dedos. Sem perspectivas de melhora, muitos pacientes acabam por se verem obrigados a conviver com um membro sem função e enfrentam várias dificuldades de adaptação. Estas dificuldades se refletem desde atividades mais simples do seu dia a dia como se vestir, tomar banho e cuidar de si mesmo independentemente, até atividades mais complexas como preparar uma refeição, dirigir e trabalhar. Em busca de uma melhor qualidade de vida frente às suas limitações, estes pacientes são encaminhados aos serviços de reabilitação e apresentam grande desafio para a atuação dos profissionais de saúde.

A prescrição, projeto, fabricação, verificação e treino de órteses e adaptações fazem parte das intervenções utilizadas pelo terapeuta ocupacional com indivíduos apresentando disfunções físicas, com objetivo de recuperar a função e melhorar o desempenho ocupacional. Porém, a maioria das órteses atualmente disponíveis para lesões do plexo braquial, são utilizadas com objetivo de posicionar o membro superior e aliviar a dor, sem oferecer funcionalidade ao membro lesado (PERRY et al., 1974; WYNN PARRY, 1997). As poucas órteses funcionais existentes são, em sua maioria para o braço (KOHLMEYER et al., 1990; PERRY, 1974), sendo raras as órteses funcionais para mão que, por sua vez, foram desenvolvidas para atender pacientes tetraplégicos (ALON, 2003; BENJUYA; KENNEY, 1990; PINTO, 1999; PROCHAZKA et al., 1997, WIERZBICKA; WIEGNER, 1996). Essas usam do movimento do punho para potencializar o movimento dos dedos (tenodese) ou exigem a contração ativa de músculos localizados no antebraço (TROMBLY; RANDOMSKI, 2005; PINTO, 1999; HARVEY, 1996; KILGORE et al., 1989), não podendo ser usada por indivíduos com ausência destes movimentos, como acontece na maioria dos tipos de lesões do plexo braquial. Outro problema é que, geralmente, as órteses são confeccionadas de materiais rígidos, apresentam grande volume, sendo pouco aceitáveis esteticamente (GREENFIELD, 1992; LANGDON, 1992). Além disto, a maior parte dessas órteses são complexas em termos de mecânica e controle (PETROFF et al., 2001; ROMILLY et al., 1994; SLACK; BERBRAYER, 1992), são importadas e, não raro, de alto custo, fazendo com que esteja muito além da disponibilidade financeira da maioria dos pacientes no Brasil.

Além de oferecer bom desempenho funcional, é importante que as órteses que sejam leves, portáteis, que não interfiram na deambulação, sejam de fácil controle, de baixo custo e de boa aparência estética. É importante também que estas órteses sejam socialmente aceitáveis, não chamem a atenção e não revelem a extensão da incapacidade de seu usuário.

Diante da necessidade de dispositivos mais eficázes, capazes de possibilitar a função na mão, foi desenvolvido uma órtese funcional para mão definida como Luva Funcional (ROCHA, 2007; ROCHA et al., 2007; MENESES, 2005; MENESES, et al., 2005). A luva funcional é composta por uma luva de tecido acoplada a tendões artificiais, um motor, um circuito e eletrodos de superfíce. O acionamento do sistema é realizado por 
meio da captação de sinais mioelétricos de músculos previamente selecionados. Os testes preliminares realizados em bancada com o protótipo da Luva Funcional mostraram seu funcionamento satisfatório, demostrando o potencial em auxiliar indivíduos com paralisias em mão e punho (MENESES, et al., 2005, 2008; MENESES, 2005). Outro estudo preliminar, cujo objetivo foi verificar o uso da órtese luva funcional em um indivíduo com paralisia em mão e punho devido lesão do plexo braquial, foi realizado e demonstrou resultados satisfatórios, porém sendo necessário estudos com amostras maiores (MENESES, 2009).

O objetivo deste trabalho foi descrever os primeiros testes de um protótipo de órtese funcional para mão, conhecida como luva funcional, em três indivíduos adultos com paralisia em mão e punho, devido a lesão do plexo braquial.

\section{MATERIAIS E MÉTODOS}

Este trabalho foi aprovado pelo Comitê de Ética em Pesquisa da Universidade Federal de Minas Gerais UFMG (Parecer n ETIC 368/06) e pelo Comitê de Ética em Pesquisa da Secretaria Municipal de Saúde de Belo Horizonte (Protocolo 016/2007).

Foi realizado um estudo experimental com adultos com paralisia em mão e punho devido à lesão de plexo braquial.

Os critérios de admissão foram: indivíduos que não apresentassem movimentos ativos em mão e punho devido lesão de plexo braquial em um dos lados do corpo; tempo mínimo de dois anos após a lesão ou após os procedimentos cirúrgicos realizados; quadro neurológico estável (relatório fornecido pelo médico do paciente relatando a ausência de perspectiva de regeneração nervosa ou ausência de indicações para cirurgias adaptativas); idade igual ou superior a 18 anos; movimentação passiva completa das articulações do punho, da mão e dos dedos; presença de contração muscular ativa de pelo menos dois músculos localizados na cintura escapular ou no membro superior (podendo ser do mesmo lado da lesão ou contralateral) para a ativação da órtese; capacidade de entender aos comandos para o aprendizado do mecanismo de acionamento da órtese. Foram excluídos desta pesquisa indivíduos que apresentaram limitações nos movimentos de flexão e extensão passiva dos dedos; doenças degenerativas progressivas; idade inferior a 18 anos; déficit cognitivo que dificulte a compreensão das orientações quanto ao uso da órtese e seu treinamento e lesões de pele nos locais de colocação da órtese.

Os pacientes selecionados foram esclarecidos sobre os objetivos do estudo e assinaram o termo de consentimento livre e esclarecido. Para cada paciente foi confeccionado uma órtese, respeitando suas características e necessidades individuais.

As avaliações e testes foram realizados no setor de Terapia Ocupacional do Centro Geral de Reabilitação (CGR), em Belo Horizonte, Minas Gerais, no período de agosto de 2007 a agosto de 2008. Todos os participantes foram informados que usariam a órtese somente durante os testes clínicos, sob supervisão do terapeuta ocupacional responsável pela pesquisa e que esta não poderia ser levada para casa. Foram informados também que, ao término da pesquisa, as órteses não seriam doadas nem vendidas aos pacientes, permanecendo no Laboratório de Bioengenharia da UFMG para testes futuros.

\section{Descrição da órtese luva funcional}

O protótipo da órtese luva funcional (Patente de número PI0504704-8) foi constituída por uma luva de tecido equipada com tendões artificiais, um músculo eletromecânico e um sistema de acionamento mioelétrico.

A escolha do material para a confecção da luva foi baseado nos critérios de flexibilidade para permitir os movimentos dos dedos, estética e conforto. O material escolhido para a confecção das luvas de teste foi tecido de lycra anti-alérgica, com porosidade de 50\% para permitir a transpiração da pele. Apesar de inconvenientes como pouca durabilidade e dificuldade de limpeza, este material foi escolhido para a confecção do protótipo da luva porque permite a movimentação dos dedos em flexão e extensão sem oferecer grande resistência, por ser de fácil manipulação durante as etapas de construção e por apresentar baixo custo.

A luva foi construída com duas camadas. A primeira camada fica em contato com a pele do paciente e serve para a fixação dos tendões artificiais e para proteção da pele do usuário. A segunda camada tem como finalidade cobrir e proteger todo o sistema interno fornecendo uma estética mais agradável. A região ventral de cada dedo da luva, contém texturas antiderrapantes, a fim de facilitar a preensão, impedindo que os objetos escorreguem da mão.

Entre as duas camadas da luva foi colocada uma tala de material termomoldável, confeccionada nos moldes específicos de cada paciente. Esta tala tem a finalidade de posicionar a articulação do punho em leve extensão (aproximadamente 20 graus) e o polegar em abdução palmar (aproximadamente 35 graus), além de fixar o sistema de condução dos tendões flexores artificiais ao músculo eletromecânico. Para os tendões flexores artificiais, foram utilizados fios de monofilamentos com adequada flexibilidade e resistência a tração.

Ainda entre as duas camadas de tecido, na parte 
dorsal da tala, existe o sistema responsável pela extensão dos dedos. Este sistema é constituído por elástico, fixo aos tendões artificiais extensores em sua porção distal e fixo na tala por meio de ganchos em sua porção proximal. Os ganchos facilitam a instalação e ajuste do elástico, que por sua vez é protegido por uma canaleta adesiva articulada de material plástico. O grau de extensão dos dedos pode ser regulado por meio da utilização de diferentes elásticos, apresentando graus variados de resistência (quanto maior o grau de resistência do elástico, maior será o grau de extensão dos dedos).

O músculo artificial eletromecânico utilizado foi um servo DS8711 da JR acoplado a uma polia de $42 \mathrm{~mm}$ de diâmetro. A escolha do motor baseou-se nos seguintes critérios: controle do ângulo de rotação, alto torque, baixo ruído, volume e peso reduzidos. O controle do ângulo de rotação é importante para que o controle do grau de extensão e flexão dos dedos seja realizado de forma segura, evitando movimentos além do limite estabelecido. A configuração do motor e da polia proporcionou a melhor razão entre torque e deslocamento dos tendões (ROCHA, 2007), de forma a permitir os graus de flexão e extensão dos dedos desejados. O movimento de flexão dos dedos ocorre quando o motor elétrico é acionado no sentido horário. Quando o motor é acionado em sentido anti-horário, permite a extensão dos dedos, que é realizada pelo elástico fixo na parte dorsal da tala. Desta forma, a Luva Funcional realiza passivamente os movimentos de flexão e extensão dos dedos (articulações metacarpofalangeanas e interfalangeanas dos dedos II ao V), substituindo a função da musculatura paralisada (flexores e extensores dos dedos).

A Luva Funcional é controlada pelo próprio usuário por meio de sinais mioelétricos detectados por eletrodos de superfície que podem ser colocados sobre dois músculos ou dois grupos musculares. Um músculo ou grupo muscular é responsável pela abertura da mão e o outro para o seu fechamento. Quando um músculo contrai, um sinal elétrico é captado e enviado para uma unidade de controle. Esta unidade de controle identifica a ação de cada músculo e, de acordo com a interpretação da lógica de controle, emite o comando para o motor girar em sentido horário ou antihorário, abrindo ou fechando a mão, conforme o desejado pelo seu usuário (MENESES, 2005; ROCHA, 2007). Quando os dois músculos são ativados simultaneamente, a órtese permanece sem movimentos. Independente do número de unidades motoras ativadas (no músculo), o motor irá operar em velocidade constante até que o músculo finalize sua contração, ou o motor chegue a seu limite máximo de rotação.

Durante os testes de com a Luva Funcional, uma tipóia de tecido foi utilizada para posicionar o membro superior lesado dos pacientes em flexão da articulação do cotovelo (aproximadamente $90^{\circ}$ ) e posição neutra da articulação do antebraço (entre pronação e supinação). Uma espuma foi usada para posicionar a articulação do ombro entre rotação interna e externa. Desta forma foi possível manter a mão e o punho livres para a preensão de objetos. O uso da tipóia teve como objetivo assegurar que fosse avaliada apenas a função da mão, independente do paciente apresentar ou não função em outras articulações da extremidade superior como ombro, cotovelo e antebraço.

\section{Instrumentos de teste}

Foi realizada ampla pesquisa na literatura a procura de instrumentos padronizados apropriados para testar a capacidade de preensão da mão. A maioria dos testes encontrados avalia a agilidade e destreza da mão (DESRISIERS, et al., 1997; GARDER, 1979; MATHIOWETZ, et al., 1985;) bem como o desempenho em atividades de vida diária (HUDAK et al., 1996). Sabendose que a função da mão depende de outras variáveis como força e capacidade de movimento em outras articulações proximais (ombro, cotovelo e antebraço), muitos destes instrumentos se mostraram inadequados. Frente a esta dificuldade de encontrar instrumentos que avaliam a capacidade de preensão da mão, independente do paciente apresentar ou não função no braço, decidiu-se utilizar alguns instrumentos, descritos a seguir, com as devidas adaptações.

\section{Teste para Desempenho em Atividades Unimanuais}

Para avaliar a capacidade de preensão de objetos, foi utilizado parte do "Grasp Release Test" (WUOLLE et al., 1994) que requer que o indivíduo segure, mova e solte dentro de uma caixa cada um de cinco objetos de diferentes formas, pesos e tamanhos. Os objetos 1 e 2 (pino e o cubo de madeira) representam objetos pequenos e leves como uma caneta ou pedaços de comida, adequados para avaliar a função de pinça trípode. Os objetos 3, 4 e 5 (cilindros de plástico e fita de videocassete) representam objetos maiores e mais pesados como um copo e um livro, adequados para avaliar a função de preensão palmar. Além da preensão e soltura dos 5 objetos, durante o teste original, também é solicitado que o indivíduo segure um pino e realize uma força na direção vertical. Esta tarefa foi considerada adequada pelos autores do teste para representar a capacidade para se perfurar pedaços de frutas, vegetais cozidos e carne com um 
garfo. Devido ao fato de que, durante os testes com a órtese Luva Funcional, os pacientes estarem utilizando a tipóia para braço que impede movimentos e forças na direção vertical, a última tarefa foi excluída do teste (segurar um pino e realizar uma força na direção vertical).

As instruções para o Teste de Função Unimanual foram as seguintes: Segure o pino de madeira e solte-o dentro da caixa; Segure o cubo de madeira e solte-o dentro da caixa; Segure o cilindro de plástico (100g) e solte-o dentro da caixa; Segure a fita de videocassete e solte-a dentro da caixa; Segure o cilindro de plástico (500g) e solte-o dentro da caixa. O uso da mão contralateral foi permitido apenas para estabilização inicial do objeto. A seqüência de manipulação foi repetida três.

\section{Teste para Desempenho em Atividades Bimanuais}

Para verificar a capacidade de realizar atividades bimanuais com o uso da Luva Funcional, foram selecionadas algumas tarefas que exigem o uso das duas mãos. Neste teste, a órtese Luva Funcional foi usada como mão auxiliar para estabilizar e posicionar objetos de forma a permitir a manipulação pela mão dominante (mão preservada). $O$ teste compreendeu cinco tarefas listadas a seguir:

1. Segurar uma folha de papel com a órtese e cortála com uma tesoura usada pela mão dominante;

2. Segurar uma caneta com a órtese e retirar a tampa com a mão dominante;

3. Segurar um copo de plástico rígido vazio com a órtese e enchê-lo com líquido, usando a mão dominante;

4. Segurar um copo de plástico rígido com líquido com a órtese e misturar açúcar segurando uma colher com a mão dominante;

5. Segurar um recipiente com tampa de rosca (creme dental) com a órtese, retirar a tampa com a mão dominante e colocar creme dental na escova.

\section{Questionário para avaliar a satisfação do cliente com o uso da órtese Luva Funcional}

Um questionário foi construído apresentando questões relativas ao conforto, funcionalidade e satisfação com o uso da Luva Funcional.

O trabalho foi dividido em duas fases. A primeira fase teve o objetivo de selecionar a musculatura adequada para acionamento do sistema eletromecânico e realizar o treinamento dos pacientes para contração e relaxamento de cada grupo muscular de forma individualizada. Um Módulo de Treinamento foi desenvolvido para auxiliar os usuários a aprenderem a controlar a órtese Luva Funcional. O Módulo de Treinamento oferece feedback visual, por meio de dois diodos emissores de luz (Light Emitting Diode - LED) de cores diferentes (verde e vermelho), para as ações de abrir e fechar a mão. Quando o paciente ativava a musculatura responsável pela abertura da mão, o LED verde acendia e quando ele contraia a musculatura responsável pelo fechamento da mão o LED vermelho acendia. Se os dois LEDs acendessem, significava que o paciente estava ativando simultaneamente ambos os músculos e, por isso, o sistema não era acionado. Foram utilizados eletrodos de superfície passivos auto-adesivos descartáveis, modelo 2223 (3M, EUA).

Na segunda fase foram aplicados os instrumentos de Teste de Função Unimanual e Bimanual e o Questionário de Satisfação. Todos os testes foram registrados por meio de filmagens.

\section{Resultados e discussão}

Paciente 1: sexo masculino, 41 anos, sofreu lesão completa do plexo braquial do lado esquerdo (avulsão de C5 a T1) devido acidente de moto em abril de 1991. Apresenta dominância direita.

Paciente 2: sexo feminino, 25 anos, sofreu lesão completa de plexo braquial direito(avulsão de C5 a T1) em novembro de 2001 devido a um acidente de moto. Apresenta dominância direita.

Paciente 3: sexo feminino, 24 anos, foi vítima de atropelamento em setembro de 2004, sofrendo lesão completa de plexo braquial esquerdo (avulsão de C5 a T1). Apresenta dominância esquerda.

Fase 1: seleção e treinamento da musculatura

Foram realizados testes de força manuais para a identificação dos músculos disponíveis para o controle mioelétrico e para a determinação precisa dos locais para a colocação dos eletrodos. Os músculos selecionados para ativação do sistema eletromecânico foram trapézio fibras superiores e elevador de escápula (responsáveis pelo movimento de elevação escapular) e os músculos trapézio fibras médias e rombóides (responsáveis pelo movimento de retração escapular). Nesta fase os pacientes aprenderam a contrair e relaxar cada grupo muscular de forma independente, controlando, de forma voluntária, o 
comando para acender e apagar as luzes do Módulo de Treinamento.

Fase 2: aplicação dos instrumentos de teste.

O primeiro instrumento a ser testado foi o "Teste de Função Unimanual”. Um teste preliminar foi administrado para cada objeto a fim de determinar se os pacientes entenderam todas as instruções do teste e para selecionar os objetos que fariam parte do teste principal. Durante o teste preliminar os três pacientes conseguiram manipular todos os objetos sem dificuldades. Portanto, todos os objetos foram incluídos no teste principal. Os três pacientes conseguiram manipular todos os objetos do teste demonstrando 100\% de sucesso na manipulação de todos os objetos.

O segundo instrumento testado foi o "Teste de Função Bimanual”. Todos os três pacientes conseguiram completar todas as tarefas, com exceção da tarefa de número 5, que foi realizada parcialmente (Tabela 1). Todos foram capazes de segurar o creme dental com a órtese e retirar a tampa com a mão dominante, mas não conseguiram apertar o creme dental de forma a colocá-lo na escova de dente. Uma explicação para o fato de que os pacientes não conseguiram completar a tarefa de número 5 é que esta é a única tarefa do Teste de Função Bimanual onde o membro vestido com a órtese é utilizado como membro dominante e não auxiliar. Caso a tarefa fosse desempenhada com o creme dental sendo apertado pela mão dominante e a escova sendo segurada pela mão com a órtese, é possível que a tarefa pudesse ser desempenhada com sucesso. Além disto, a tarefa 5 consiste em duas etapas: a primeira é segurar o creme dental e tirar a tampa, que foi realizada com sucesso e a segunda é apertar o creme dental e colocá-lo na escova de dentes. A figura 1 mostra os pacientes utilizando a órtese Luva Funcional e realizando tarefas do Teste de Função Bimanual.

Tabela 1. Resultado do Teste de Função Bimanual

\begin{tabular}{|c|c|c|c|c|c|c|c|}
\hline \multirow[b]{2}{*}{1} & \multirow{2}{*}{\begin{tabular}{|l}
\multicolumn{1}{c}{ Tarefas } \\
$\begin{array}{l}\text { Segurar folha de papel com a órtese e cortá-la com uma tesoura usada pela mão } \\
\text { dominante. }\end{array}$
\end{tabular}} & \multicolumn{2}{|c|}{ Paciente1 } & \multicolumn{2}{|c|}{ Paciente2 } & \multicolumn{2}{|c|}{ Paciente3 } \\
\hline & & Sim & & Sim & & Sim & \\
\hline 2 & Segurar caneta com a órtese e retirar a tampa com a mão dominante & Sim & & Sim & & Sim & \\
\hline 3 & $\begin{array}{l}\text { Segurar copo de plástico rígido vazio com a órtese e enchê-lo com líquido, usando a } \\
\text { mão dominante }\end{array}$ & Sim & & Sim & & Sim & \\
\hline 4 & $\begin{array}{l}\text { Segurar copo de plástico rígido com líquido com a órtese e misturar açúcar segurando } \\
\text { uma colher com a mão dominante }\end{array}$ & Sim & & Sim & & Sim & \\
\hline 5 & $\begin{array}{l}\text { Segurar recipiente com tampa de rosca (creme dental) com a órtese, retirar a tampa } \\
\text { com a mão dominante e colocar creme dental na escova }\end{array}$ & & Não & & Não & & Não \\
\hline
\end{tabular}

Figura 1. Pacientes utilizando a órtese Luva Funcional e realizando tarefas do Teste de Função Bimanual

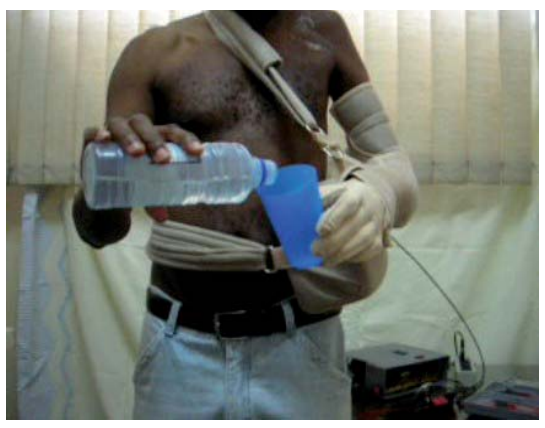

Paciente 1 desempenhando a tarefa 3 Segurar copo de plástico rígido vazio com a órtese e enchê-lo com líquido, usando a mão dominante).

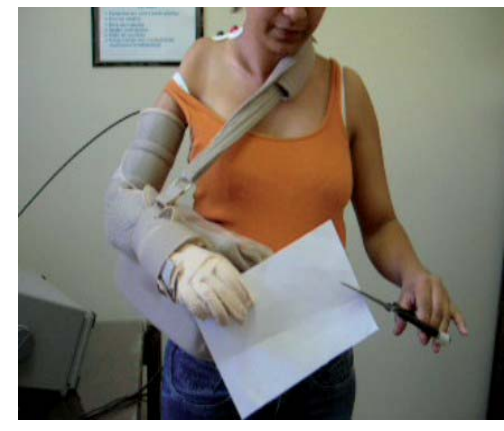

Paciente 2 desempenhando a tarefa 1 - Segurar folha de papel com a órtese e cortá-la com uma tesoura usada pela mão dominante).

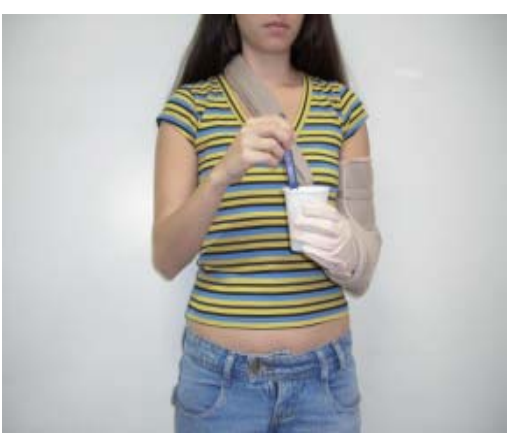

Paciente 3 desempenhando a tarefa 4 Segurar copo de plástico rígido com líquido com a órtese e misturar açúcar segurando uma colher com a mão dominante). 
O terceiro instrumento testado foi o "Questionário de Satisfação”, cujo objetivo foi verificar o grau de conforto, funcionalidade e de satisfação dos pacientes com o uso da Luva Funcional. Os pacientes 2 e 3 responderam SIM a todas os ítens e o paciente 1 respondeu "SIM" para 9 dos 12 ítens. Os ítens marcados com resposta "NÃO” foram analisados como ítens que precisam ser aperfeiçoados e demonstram a necessidade de trabalhos futuros, para que melhorias sejam realizadas. A Tabela 2 apresenta os resultados dos Questionários de Satisfação dos três pacientes que participaram dos estudos de caso.

Tabela 2. Resultado dos Questionários de Satisfação

\begin{tabular}{|c|c|c|c|c|c|c|c|}
\hline & & Tarefas & Paci & nte1 & Paci & Pac & ente3 \\
\hline \multirow{4}{*}{ Comforto } & 1 & $\begin{array}{l}\text { A colocação da Luva Funcional foi realizada } \\
\text { com facilidade }\end{array}$ & Sim & & Sim & Sim & \\
\hline & 2 & $\begin{array}{l}\text { A retirada da Luva Funcional foi realizada com } \\
\text { facilidade }\end{array}$ & Sim & & Sim & Sim & \\
\hline & 3 & A Luva Funcional é leve & & Não & Sim & Sim & \\
\hline & 4 & O barulho da Luva Funcional não incomodou & Sim & & Sim & Sim & \\
\hline \multirow{4}{*}{ Funcionalidade } & 5 & Os eletrodos foram corretamente fixados & Sim & & Sim & Sim & \\
\hline & 6 & $\begin{array}{l}\text { O acionamento da Luva Funcional foi realizado } \\
\text { com facilidade }\end{array}$ & Sim & & Sim & Sim & \\
\hline & 7 & $\begin{array}{l}\text { O controle dos movimentos de abertura e fecha- } \\
\text { mento da mão foi realizado com facilidade }\end{array}$ & & Não & Sim & Sim & \\
\hline & 8 & $\begin{array}{l}\text { A Luva Funcional irá melhorar meu desempe- } \\
\text { nho em atividades que antes eu não conseguia } \\
\text { realizar sem ajuda }\end{array}$ & Sim & & Sim & Sim & \\
\hline \multirow{4}{*}{ Satisfação } & 9 & Eu gostei da aparência da Luva Funcional & & Não & Sim & Sim & \\
\hline & 10 & Estou satisfeito com o uso da Luva Funcional & Sim & & Sim & Sim & \\
\hline & 11 & $\begin{array}{l}\text { Recomendo o uso da Luva Funcional para outros } \\
\text { pacientes que apresentam paralisia na mão }\end{array}$ & Sim & & Sim & Sim & \\
\hline & 12 & Eu gostaria de ter uma da Luva Funcional & Sim & & Sim & Sim & \\
\hline
\end{tabular}

\section{Considerações finais}

Os três pacientes selecionados foram capazes de controlar a abertura e o fechamento da mão por meio do uso da órtese Luva Funcional. Os pacientes foram capazes de segurar e soltar os cinco objetos do Teste de Função Unimanual e foram capazes de completar as tarefas do Teste de Função Bimanual, com exceção da tarefa de número cinco, que foi parcialmente realizada. É importante relatar que a órtese Luva Funcional favorece apenas movimentos grosseiros de abertura e fechamento da mão e não oferece destreza e agilidade para atividades que exigem coordenação motora fina dos dedos. Todos os três pacientes apresentaram alto índice de satisfação com o uso da órtese Luva Funcional. 
A órtese Luva Funcional apresenta algumas vantagens importantes para seu uso. Pacientes com paralisias na mão necessitam movimentar suas articulações repetidas vezes por dia em toda a amplitude de movimento com o objetivo de prevenir deformidades e limitações na amplitude de movimento. Como a órtese Luva Funcional realiza passivamente os movimentos de flexão e extensão dos dedos, seu uso pode auxiliar na prevenção de contraturas e deformidades. Outra vantagem é que para seu uso não é necessário que o usuário tenha o movimento ativo do punho ou apresente músculos ativos na região do antebraço. Além disso, pode ser utilizada por indivíduos com paralisia completa de todo o membro superior, desde que utilizada juntamente com órteses para posicionamento do braço, como uma tipóia.

A órtese Luva Funcional apresenta o potencial de auxiliar indivíduos com paralisias em mão e punho devido a lesão do plexo braquial no desempenho de suas atividades diárias, de lazer e de trabalho. A Luva Funcional também pode ser confeccionada com outros materiais como couro, oferecendo o benefício de facilidade de limpeza e maior durabilidade. Porém mais estudos são necessários para aperfeiçoar o equipamento, para verificar o potencial de auxílio no desempenho de atividades do dia a dia e verificar seu potencial de uso em indivíduos apresentando paralisias devido outras patologias.

Reconhecimento: Esse projeto foi financiado com recursos do Conselho Nacional de Desenvolvimento Científico e Tecnológico- CNPq e da Fundação de Amparo à Pesquisa de Minas Gerais - FAPEMIG.

MENESES, K. V. P.; ROCHA, D. N.; CORRÊA JÚNIOR, F. L.; SONO, T.; OLIVEIRA, A. L.; PINOTTI, M. Application of a functional hand orthosis in individuals with brachial plexus injuries. Rev. Ter. Ocup. Univ. São Paulo, v. 23, n. 1, p. 34-43, jan./abr. 2012.

\begin{abstract}
One of the diseases that cause severe disability and that directly affect the individual's social participation and quality of life is the brachial plexus injury. One of the interventions widely used in the rehabilitation program of the individual who suffered brachial plexus injury is the manufacture and prescription of orthoses. However the majority of currently available orthosis for brachial plexus injuries, are used in order to positioning the upper limb and to relieve pain, without offering the functionality to injured limb. The aim of this study was to describe the first tests of a prototype orthosis for hand function, known as Functional Glove in adult patients with paralysis in the hand and wrist due to brachial plexus. This research consisted of experimental studie, attended by three patients. Three instruments were used: Unimanual Function Test, Bimanual Function Test and Satisfaction Questionnaire. The results showed that the patients managed control the opening and closing of the orthosis by means of myoelectric signals picked up by surface electrodes placed over the selected muscles, allowing manipulation of objects in unimanual and bimanual activities. The patients reported high index of satisfaction with the use of Functional Glove.
\end{abstract}

KEYWORDS: Self-help devices; Gloves, protective/utilization; Brachial plexus/Injuries, Rehabilitation.

\title{
REFERÊNCIAS
}

ALON, G.; MCBRIDE, K. Person With C5 or C6 Tetraplegia Achieve Seleted Functional Gains Using a Neuroprosthesis. Arch Phys Med Rehabil, 84: p.119-24, 2003.

BENJUYA, N.; KENNEY, S. B. Myoelectric hand orthosis. Journal of Prosthetics and Orthotics. v. 2, n.2, p.149-154, 1990.

CONCEIÇÃO, L.M. Traumatismos do plexo braquial. In:
FREITAS, P.P. Reabilitação da mão. Atheneu, 2005, cap.16, p.231-253.

DESRISIERS, J et al. The Minnesota Manual Dexterity test: Reliability, validity and reference values studies with healthy elderly people. Canadian J Occupational Therapy, v. 64, n.5, p. 270-276, 1997.

FLORES, L.P. Estudo epidemiológico das lesões traumáticas de 
plexo braquial em adultos. Arq. Neuro-Psiquiatr. v.64 n.1 São Paulo, mar. 2006.

GARDER, RA; BROMAN, M. The Purdue Pegboard: normative data on 1334 school children. J Clinical Psycology, v.1, p. 15662, 1979.

GREENFIELD, J. Rancho Los Amigos Medical Centre. Downey, California, Personal Communication, May, 1992.

HARVEY, L. Principles of conservative management for a Nonorthotic tenodesis grip in tetraplegics. Journal of Hand Therapy, v. 9, n.3, p. 238-242, jul-sep.1996.

HOFFER, M.M. et al. Functional recovery and orthopedic management of brachial plexus injuries. JAMA, v.27, p.24672470, November, 1981.

HUDAK, P.; AMADIO, PC; BOMBARDIER, C. The upper extremity collaborative group; Development of na Upper Extremity Outcome Measure: The DASH (Disabilities of the Arm, Shoulder and Hand). American Journal of Industrial Medicine, v. 29, p. 602-608, 1996.

KILGORE, K.L. et al. Synthesis of Hand grasp Using Functional Neuromuscular Stimulation. Transactions on Biomedical engineering, v.36, n.7, p.761-70, jul. 1989.

KOHLMEYER, K. M.; WEBER, C.G., YARKONY, G.M. A New Orthosis for Central Cord Syndrome and Brachial Plexus Injuries. Arch. Phys. Med. Rehabil, v. 71, p. 1006-1009, november, 1990.

LANGDON, S. Rancho Los Amigos Medical Centre. Downey, California, Personal Communication, May, 1992.

LEFFERT, R.D. Rehabilitaation of the patient with an injury to the Brachial Plexus. In: HUNTER, JM; MACKIN, EJ; CALLAHAN, AD. Rehabilitation of the Hand: Surgery and Therapy. 4 ed, Mosby-year Book, Inc., v.2, cap. 35, p.635-645, 1995.

MATHIOWETZ, V. et al. Adult norms for the Box and Block test of manual dexterity. American Journal Occupational Therapy. Jun, v.39, n.6, p. 386-91, 1985.

MIDHA, R. Epidemiology of Brachial Plexus Injuries in a Multitrauma Population. Neurosurgery; v. 40, p.1182-1189, 1997.

MENESES, K. V. P. de et al. Aplicação da luva funcional. Rev. Ter. Ocup. Univ. São Paulo, v. 20, n. 2, p. 92-100, maio/ago. 2009.

MENESES, et al., Testes Preliminares de um Protótipo de órtese funcional para mão. Revista de Terapia Ocupacional da Universidade de São Paulo. v.19, n.3, p. 193-201, 2008.

MENESES, K.V.P. Desenvolvimento de um Protótipo de Órtese Funcional Para Mão. 69p. Dissertação (Mestrado em Engenharia
Mecânica) - Escola de Engenharia, Universidade Federal de Minas Gerais, Belo Horizonte, 2005.

MENESES, K.V.P. Avaliação funcional de uma órtese para mão com músculos artificiais eletromecânicos em pacientes com lesão de plexo braquial. Tese (Doutorado em Engenharia Mecânica) - Escola de Engenharia, Universidade Federal de Minas Gerais, Belo Horizonte, 2008.

MENESES, K.V.P.; ROCHA, D.N.; REZENDE, H.M.; CORRÊA, M.F.S.; SCHULTZ, O. F.L.; BARROSO, P.N.; PINOTTI, M. Development of a Functional Hand Orthosis. 18th International Congress of Mechanical Engineering. November 6-11, 2005, Ouro Preto, MG.

ÖGCE, F E; ÖZYALÇIN, H. A myoelectrically controlled shoulder-elbow orthosis for unrecovered brachial plexus injury. Prosthetics and Orthotics International, v.24, p.252-255, 2000.

PERRY, J. et al. Orthoses in Patients with Braquial Plexus Injuries. Arch Phys Med Rehabil. v. 55, Mar 1974.

PETROFF, N. et al. Fuzzy-control of a hand orthosis for restoring tip pinch, lateral pinch, and cylindrical prehensions to patients with elbow flexion intact. IEEE Transactions on neural systems and rehabilitation engineering, v.9, n.2, p.225-231, jun. 2001.

PINTO, S.A.P. Projeto, implementação e avaliação de uma órtese funcional robotizada de mão. Dissertação de Mestrado, Departamento de Ciência da Computação UFMG, 1999.

PROCHAZKA, A. et al. The Bionic Glove: an Electrical Stimulator Garment That Provides Controlled Grasp and Hand Opening in Quadriplegia. Arch Phys Med Rehabil. v.78, p.608614, jun. 1997.

ROCHA, D.N. Desenvolvimento do sistema de controle de uma órtese de mão. Dissertação (Mestrado em Engenharia Mecânica) - Escola de Engenharia, Universidade Federal de Minas Gerais, Belo Horizonte, 2007.

ROCHA, D.N., MENESES, K.V.P.; AFONSO, A.A.; CORRÊA, M.F.S.; BATISTA, C.E.P.; PINOTTI, M. Controle de Força de Preensão para uma Órtese de mão por meio da Análise da Corrente Elétrica do Atuador. Revista Matéria, v. 12, n. 1, p. 173 - 178, 2007. Disponível em: http://www.materia.coppe.ufrj. br/sarra/artigos/artigo10865.

ROMILLY, D.P., et al. A functional task: Analysis and motion simulation for the development of a powered upper-limb orthosis. IEEETransactions on Rehabilitation Engeneering, v. 2, n.3, p. 119-129, sep 1994.

SALTER, R.B. Distúrbios e lesões do sistema musculoesquelético. 3 ed., Medsi, 2001, cap.12, p.307-343.

SLACK, M; BERBRAYER, D. A Myoelectrically Controlled Wrist-Hand Orthosis for Brachial Plexus Injury: A Case Study. 
MENESES, K. V. P. et al. Aplicação de uma órtese funcional. Rev. Ter. Ocup. Univ. São Paulo, v. 23, n. 1, p. 34-43, jan./abr. 2012.

Journal of Prosthetic and Orthotics, v.4, n.3, p.171-174, 1992.

TROMBLY, C.A.; RADOMSKI, M.V. Occupational Therapy for Physical Dysfunction. 5 ed., Baltimore, Williams \& Wilkins, 2005.

WIERZBICKA, M.M., WIEGNER, A.W. Orthosis for Improvement of Arm Function in C5/C6 Tetraplegia. Journal of Prosthetics and orthotics. v.8, n.3, p. 86-92, 1996.

WYNN PARRY, C. B. Some Aspects of the History of
Rehabilitation of the Hand. Journal of Hand Therapy. p.199-205, July/September, 1997.

WORLD HEALTH ORGANIZATION.Towards a Common Language for Functioning, Disability and Health - ICF. [WHO/ EIP/GPE/CAS/01.3] Genebra; 2002.

WUOLLE, K.S. et al. Developmet of a quantitative hand grasp and release test for participants with tetraplegia using a hand neuroposthesis. J Hand Surg. v.19A, p.209-218, 1994.

Recebido para publicação: 26/05/2011

Aceito para publicação: 02/04/2012 